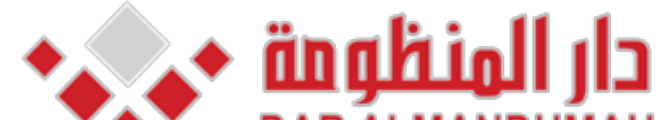 DAR ALMANDUMAH

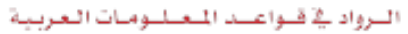

LA TRADUCCIÓN DE TEXTOS DE CONTENIDO ISLÁMICO : DIDÁCTICA Y ASPECTOS TEXTUALES

مجلة كلية اللغات والترجمة جامعة الازهر - كلية اللغات والترجمة

Zaghloul, Ahmed Kamal ₹ع نعم

2014

يوليو

$94-120$

752816

بحوث ومقالات

AraBase

الترجمة، طرق التدريس، التربية الإسـلامية

http://search.mandumah.com/Record/752816

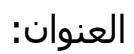

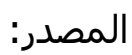

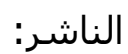

المؤلف الرئيسـي:

المجلد/العدد:

محكمة:

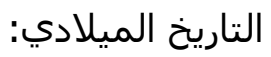

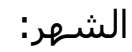

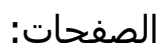

رقم MD:

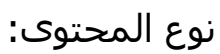

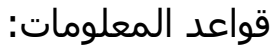

مواضيع: - ت

رابط: 


\section{LA TRADUCCIÓN DE TEXTOS DE CONTENIDO ISLÁMICO: DIDÁCTICA Y ASPECTOS TEXTUALES}

DR. AHMED KAMAL ZAGHLOUL 


\section{LA TRADUCCIÓN DE TEXTOS DE CONTENIDO ISLÁMICO... \\ DR. AHMED KAMAL ZAGHLOUL}

\section{Introducción}

El presente estudio se enmarca en el campo específico de la Traducción Religiosa (árabe-español) y pretende avanzar en el análisis y caracterización de una noción poco estudiada hasta la fecha: la didáctica de la traducción de textos de contenido islámico. Aunque hay muchos estudios que plantean temas relacionados con la traducción de textos islámicos desde una perspectiva teórica, descriptiva o crítica, casi no existen investigaciones didácticas directamente centradas en la traducción de este tipo de textos.

Los destinatarios de este trabajo son, sobre todo, estudiantes de lengua española de la Universidad de Al-Azhar en El Cairo (Egipto) ${ }^{1}$. Los dos primeros años de la carrera se centran en adquirir los conocimientos lingüísticos y culturales generales que constituyen los fundamentos del aprendizaje, y a partir del tercero se avanza hacia la adquisición del conocimiento experto, aproximándose a la traducción en los distintos ámbitos de especialidad. Se estudian, entonces, entre otras asignaturas lingüísticas y literarias, las distintas modalidades de la traducción especializada, como la científico-técnica, la administrativo-jurídica, la económica, la literaria y la religiosa. Los docentes deben ayudar a los alumnos durante los últimos dos años a adquirir competencias relacionadas más con el mercado laboral. Por eso, la asignatura "Traducción religiosallse ubica en el tercer y cuarto curso del título de Licenciado en Lengua y Literatura española.

\footnotetext{
1 La Universidad de Al-Azhar es uno de los centros de educación superior más importantes de Egipto, con más de medio millón de alumnos, y, a la vez, el principal centro de enseñanza y pensamiento sunní en el mundo musulmán.
} 


\section{LA TRADUCCIÓN DE TEXTOS DE CONTENIDO ISLÁMICO... \\ DR. AHMED KAMAL ZAGHLOUL}

Hay varias razones de peso que justifican la enseñanza de la traducción de textos islámicos en este plan de estudios, entre las cuales destaca la existencia de una fuerte demanda del mercado laboral, ya que la importancia de la traducción islámica, sobre todo, en países árabes ha aumentado considerablemente en los últimos años. Además, los alumnos de la universidad de teología islámica tienen normalmente la motivación necesaria para aprender la traducción de textos islámicos.

Una postura bastante extendida en la actualidad es que no existe un método único de aprendizaje de la asignatura objeto de estudio. Cada docente parte de su propia experiencia personal, que puede variar de un profesor a otro. Algunos prestan más atención al conocimiento y almacenamiento de términos islámicos; otros, a la comprensión y análisis de los problemas que pueden enfrentar el traductor de textos islámicos. El enfoque profesional y metodológico que aquí se propone se sirve de observaciones procedentes de la labor profesional desempeñada, de las condiciones del mercado laboral y de las propias lecturas sobre la teoría de la traducción, sobre todo, la enseñanza de la misma.

A partir de lo expuesto, este estudio tiene por objetivo sistematizar, complementar y mejorar la enseñanza de la traducción de textos islámicos que forma parte del plan de estudios de la Licenciatura en Lengua española y Traducción de algunas universidades árabes, como la Universidad de AlAzhar en El Cairo (Egipto) y la Universidad del Rey Saúd en Riad (Arabia Saudí), pretendiendo dar respuesta a la pregunta siguiente: ¿cómo se puede enseñar la asignatura de la traducción religiosa de una forma sistemática y metodológica? 


\section{LA TRADUCCIÓN DE TEXTOS DE CONTENIDO ISLÁMICO...}

DR. AHMED KAMAL ZAGHLOUL

\section{1) Posibilidad e imposibilidad de la didáctica de la traducción inversa}

Una de las normas que sigue tan fuerte en los Estudios de la Traducción es la de que la traducción debe realizarse hacia la lengua materna, y no al revés. No obstante, la traducción de los textos islámicos se desarrolla casi siempre de la lengua árabe a los otros idiomas. Además, el alumnado objeto de nuestro estudio es de nacionalidad egipcia. Por eso, resultaría conveniente plantear la problemática de la traducción inversa, teniendo en cuenta que los investigadores no se ponen de acuerdo sobre la posibilidad de enseñar la traducción inversa.

Muchos traductólogos rechazan rotundamente tanto la práctica como la didáctica de esta modalidad de traducción, entre ellos destaca el traductólogo inglés Peter Newmark, quien dice en su A Textbook of Translation:

"Doy por sentado que ustedes, lectores, están aprendiendo a traducir a la lengua en que normalmente se desenvuelven, puesto que éste es el único modo de traducir con naturalidad, exactitud y el máximo de eficacia" (1992: 17).

Otro detractor de la traducción inversa es Süss, quien insiste en que el traductor debe rehuir la traducción inversa, y por lo tanto, no deberíamos enseñarla, es decir, habría que desterrar la enseñanza de traducción inversa de los planes de estudio (cit. en Roiss, 2001: 406). Llevando al extremo esta perspectiva, algunos países, como el Reino Unido, consideran la traducción inversa contraria a la ética profesional del traductor (Mayoral y Kelly, cit. en Cómitre Narváez, 2003: 383).

Al contrario, hay otra corriente que defiende la traducción inversa, partiendo de consideraciones más prácticas, ya que esta modalidad es una 


\section{LA TRADUCCIÓN DE TEXTOS DE CONTENIDO ISLÁMICO... \\ DR. AHMED KAMAL ZAGHLOUL}

actividad corriente en el mercado laboral. Como es menester de los docentes de traducción ayudar a los estudiantes a mejorar su competencia traductora en las áreas en que probablemente van a trabajar, encontramos que la traducción inversa forma parte, como señala Wimmer (2001: 99), de los planes de estudio de muchas universidades en varios países, como, por ejemplo, en Alemania y España. Los investigadores que adoptan esta postura parten, pues, de que la traducción inversa tiene mucha importancia en la realidad profesional. Uno de los defensores de esta modalidad de traducción, Beeby Lonsdale, pone en ridículo la postura tan severa de los detractores, señalando que la traducción inversa se convierte, entre los traductores, en la Cenicienta de los Estudios de Traducción, la hermana desdichada obligada a hacer el trabajo sucio (1996: 5)².

En lo que se refiere al caso objeto de nuestro estudio, creemos que el uso de los textos cuya lengua original es el árabe sería más adecuado en la didáctica de la traducción de textos islámicos, por las razones siguientes:

1) El árabe es casi siempre la lengua original en que están escritos los textos islámicos.

2) A nivel profesional, el mercado laboral en los países árabes exige, en muchas ocasiones, que el traductor sea musulmán y que tenga conocimientos declarativos sobre las distintas disciplinas de la religión islámica, cosas que normalmente existen más en un traductor árabe.

3) La traducción inversa es un ejercicio de expresión escrita muy beneficioso para los alumnos de lengua.

\footnotetext{
${ }^{2}$ Beeby Lonsdale dice textualmente: "Translating from the mother tongue into a second language has become the Cinderella of translating among translators, translation theorists, and teachers of «real» translation".
} 


\section{LA TRADUCCIÓN DE TEXTOS DE CONTENIDO ISLÁMICO... \\ DR. AHMED KAMAL ZAGHLOUL}

\section{2) Objetivos de la enseñanza/aprendizaje de la traducción de textos}

\section{islámicos}

La enseñanza de la traducción, sea cual sea su modalidad, ha de partir de los objetivos generales pensados para la asignatura. El docente de una asignatura de traducción debe precisar, antes que nada, el conocimiento práctico de la materia que quiere que sus alumnos adquieran, y el saber teórico que quiere que ellos comprendan. A este respecto, Elena García (2007: 101) considera que:

"El objetivo fundamental de la enseñanza de la traducción, tanto general como especializada, es el desarrollo y perfeccionamiento de los conocimientos y destrezas necesarios para traducir (en términos de la teoría de la traducción, se habla de competencia traductora)".

La competencia traductora consta de una serie de subcompetencias, entre las cuales se puede hacer referencia a la lingüística, la cultural, la informática, la estratégica, la temática, la documental... Aunque sería difícil enseñar a los alumnos de los programas de lengua todas estas subcompetencias, no se puede imaginar la enseñanza de la traducción sin desarrollar dichas habilidades. A este respecto, la diferencia entre los dos programas, el de lengua y el de traducción, consiste en el papel que desempeña la competencia lingüística en ambos, pues si se otorga un papel de protagonismo didáctico en el plan de estudio de lengua, en el de traducción no es nada más que una de las distintas habilidades que debe adquirir el alumno, teniendo en consideración que se suele esperar de los alumnos de los centros dedicados a la formación de traductores que comiencen sus estudios con un cierto nivel de la destreza lingüística. Además, casi todas las asignaturas del plan de estudio de traducción se 


\section{LA TRADUCCIÓN DE TEXTOS DE CONTENIDO ISLÁMICO... \\ DR. AHMED KAMAL ZAGHLOUL}

relacionan directa e indirectamente con la traducción profesional, mientras que las del plan de estudio de lengua, como el del Departamento de Español de la Universidad de Al-Azhar, están vinculadas a la lengua, literatura y traducción didáctica y profesional.

A partir de lo expuesto en las consideraciones generales anteriores, sería necesario que el docente de la traducción religiosa precisara los objetivos de la enseñanza de este tipo de traducción. A nuestro parecer, el docente de la traducción de textos islámicos en el plan de estudio de Licenciatura en Lengua española y Traducción de la Universidad de AlAzhar debe poner más énfasis en los objetivos específicos siguientes, por su importancia en la formación de traductores aptos para desenvolverse en el mercado laboral de la traducción de textos islámicos:

1) Dominar el campo temático (competencia temática).

2) Conocer el funcionamiento del mercado laboral.

3) Clasificar y caracterizar los distintos textos islámicos.

4) Familiarizarse con el uso de obras de referencia relacionadas con el lenguaje apologético (competencia documental).

5) Dominar la terminología islámica.

A continuación abordamos detalladamente cada uno de estos objetivos en un apartado aparte.

\section{1) La competencia temática}

Igual que cualquier otra modalidad de traducción especializada, uno de los objetivos de la enseñanza de la traducción de textos islámicos consiste en capacitar a los alumnos a adquirir los conocimientos declarativos sobre el tema de especialidad, que son, en este caso, los conocimientos islámicos. 


\section{LA TRADUCCIÓN DE TEXTOS DE CONTENIDO ISLÁMICO... \\ DR. AHMED KAMAL ZAGHLOUL}

Según Kelly (2002: 14), la competencia temática comprende los conocimientos básicos sobre los campos temáticos en los que trabaja el traductor, los cuales le permiten el acceso a la comprensión del texto de origen o de la documentación adicional que emplee.

El traductor de textos islámicos debe tener los conocimientos apologéticos básicos y necesarios para la práctica de la traducción de textos de contenido islámico, dado que la traducción de este tipo de textos tiene una fuerte carga de información extralingüística sobre los saberes de la religión islámica. Si el traductor de textos islámicos tiene deficiencias en la competencia temática, es decir, no tiene suficientes conocimientos objetivos, le resultará difícil comprender el mensaje del texto árabe.

Sin embargo, el saber temático que debe poseer el traductor de este campo no debe estar al mismo nivel que el de los ulemas de la religión islámica, es decir, no es necesario ser sabio musulmán para traducir un texto islámico, ya que se trata de tipos distintos de conocimiento. Aunque el traductor no puede escribir sobre el Islam, igual que un sabio musulmán, sí cuenta con un conocimiento que le permite comprender y traducir un texto islámico especializado. Los conocimientos que necesita el traductor para poder trasladar un texto islámico son, pues, de tipo pasivo y utilitario.

En la Facultad de Lenguas y Traducción de la Universidad de AlAzhar se forma a estudiantes que, de hecho, poseen muchos conocimientos sobre el Islam. Aún más, los alumnos universitarios estudian algunas asignaturas islámicas, obligadas por la Universidad de índole islámica a todas sus facultades, y en las que se imparten saberes declarativos sobre las distintas disciplinas de la religión islámica, como la exégesis del Corán, la interpretación del Hadiz, la biografía del Profeta..., estudiadas, profundamente, por el alumnado también durante la educación secundaria. 


\section{LA TRADUCCIÓN DE TEXTOS DE CONTENIDO ISLÁMICO... \\ DR. AHMED KAMAL ZAGHLOUL}

Se proporciona, pues, a los aprendices de la asignatura Traducción Religiosa saberes declarativos útiles que les permiten familiarizarse y comprender los distintos textos islámicos, acceder a documentación especializada y enfrentarse con garantías de éxito a la traducción de dichos textos.

\section{2) El mercado laboral}

El mercado laboral de la traducción varía de un campo de traducción a otro. Uno de los objetivos de enseñar la traducción, aunque sea su campo de especialización, es dar a conocer a los alumnos el funcionamiento del mercado laboral, prestando más atención a las características que distinguen un campo de otro. Según Hurtado Albir (2001: 396), el conocimiento del mercado laboral y del comportamiento del traductor profesional forma parte de la competencia instrumental y profesional que debe adquirir el aprendiz de la traducción especializada.

Una buena forma de introducir cualquier asignatura de traducción y también de motivar al estudiante consiste en dar una idea general sobre el mundo profesional, ya que de este modo los alumnos van a percibir que esta asignatura tendrá una aplicación en la práctica profesional. Basándome en mi propia experiencia como traductor y revisor de textos de contenido islámico, pretendo en este apartado explicar el funcionamiento del mercado laboral con respecto a la traducción de este tipo de textos en Egipto.

Muchos proveedores de servicios de traducción de textos islámicos en Egipto prefieren contratar a un traductor graduado en la Universidad de AlAzhar para garantizar que éste tenga la competencia temática necesaria. La Facultad de Lenguas y Traducción de la Universidad de AlAzhar es la única en Egipto cuyos graduados cursan las distintas disciplinas del Islam desde la primaria, y a lo largo de al menos 16 años de estudios. Además, 


\section{LA TRADUCCIÓN DE TEXTOS DE CONTENIDO ISLÁMICO... \\ DR. AHMED KAMAL ZAGHLOUL}

los graduados específicamente en el programa de español son los únicos que estudian dos asignaturas de traducción religiosa durante los últimos dos cursos de la Universidad.

Casi todos los textos islámicos que necesitan ser traducidos en el mercado laboral son escritos en árabe, siendo la lengua tradicional de los estudios islámicos. La dirección de la traducción será, pues, desde el árabe al español. Dado que los proveedores de servicios de traducción prefieren, y a veces incluso exigen como una condición indispensable, que el traductor sea musulmán, la traducción será, para los traductores árabes, de dirección inversa. Como esta modalidad de traducción es una práctica común en el mundo profesional, existe normalmente en los grandes proyectos de traducción, además del traductor y revisor árabes, un editor nativo español cuyo trabajo consiste en compensar las limitaciones lingüísticas del traductor.

La mayor parte de los libros sagrados del Islam, éstos son el Corán y los libros de la tradición profética, son traducidos ya. Algunos textos, como el Corán, tienen incluso numerosas versiones españolas. Por eso, los encargos de traducción religiosa en el mercado laboral se tratan normalmente de textos religiosos no sagrados, es decir, textos de contenido islámico que no son revelados desde Alá, sino escritos por los ulemas e imanes del Islam, aunque casi siempre contienen citas del Corán y de los dichos y hechos del Profeta. Sin embargo, varias empresas o entidades que trabajan en la traducción de textos apologéticos, sobre todo las sauditas, exigen a los traductores que utilicen una determinada traducción del Corán para transmitir las citas coránicas. La versión española del Corán más utilizada para este fin es la de Melara Navío, por ser la traducción apoyada y divulgada por el Complejo del Rey Fahd para la edición del Noble Corán 


\section{LA TRADUCCIÓN DE TEXTOS DE CONTENIDO ISLÁMICO... \\ DR. AHMED KAMAL ZAGHLOUL}

en Medina. En este caso, el proveedor de servicios de traducción no permite al traductor que emplee cualquier otra traducción coránica que la antes mencionada, aunque el traductor crea que otra traducción del Corán es mejor que la de Melara.

A veces también se recurre a un especialista en los saberes islámicos cuya tarea consiste en ser una referencia religiosa para los traductores. Si el traductor, dada la dificultad del lenguaje de algunos textos árabes tradicionales, no puede entender algún término o alguna frase puede pedir la ayuda de este especialista.

La traducción de textos islámicos requiere, en muchas ocasiones, un trabajo en grupo con el fin de cumplir los plazos de entregas necesarios del cliente, razón por la cual sería necesario potenciar la capacidad de los alumnos a traducir en equipo, pues ya es una necesidad cada vez más patente en el mercado laboral.

\section{3) Clasificación y caracterización de los textos islámicos}

La primera fase de cualquier proceso de traducción es analizar el texto original. Por eso, sería necesario que el alumnado se enterase de la clasificación de los textos de contenido islámico para poder traducir cada texto de acuerdo con las características que le distinguen. A este respecto hay que tener presente que existen diferentes tipos de textos islámicos, y que cada uno de los mismos presenta sus propias peculiaridades y conlleva diferentes problemas traductológicos. A este respecto, Elena García (2007: 102) considera que "el conocimiento textual, el dominio contrastivo de las clases de texto en las dos lenguas de trabajo, es un campo fundamental en la investigación y uno de los pilares de la didáctica". 


\section{LA TRADUCCIÓN DE TEXTOS DE CONTENIDO ISLÁMICO... \\ DR. AHMED KAMAL ZAGHLOUL}

Los textos islámicos pueden ser clasificados, a grandes rasgos, en sagrados y no sagrados. Los primeros son los revelados desde Alá, que son precisamente el Noble Corán y la tradición profética, es decir, los dichos y hechos del profeta Muhammmad, dado que éste, según la creencia islámica, "no habla por propio impulso. No es sino una revelación que se ha hecho" (Corán, trad. de Julio Cortés, 53: 3-4). Los segundos son los textos escritos por los ulemas y sabio del Islam y que giran en torno de las dos fuentes antes mencionadas, tratando de explicar y sacar sentencias de las mismas. Aunque son textos no sagrados, disponen casi siempre de citas textuales del Corán y de la tradición profética. Dentro de este tipo de textos se enmarcan los textos de la exégesis del Corán, la interpretación de la tradición profética, las fetuas, los sermones de la oración del viernes, etc.

Los textos sagrados son revelados en árabe clásico, y se caracterizan, entre otras cosas, por ser muy condensos. Se trata de un breve discurso, pero lleno de sentido. Un solo vocablo o una sola frase puede tener varias interpretaciones, y todas son correctas. Ningún exegeta del Corán o del Hadiz es capaz de decir que su interpretación es la única correcta; lo que hace no es nada más que un intento para explicar algunos significados del texto sagrado, dado que los principales receptores de este texto son la gente que vivía en el tiempo de la revelación, es decir, desde hace 1400 años. En este caso, el traductor elige normalmente entre una de las tres opciones siguientes:

- transmitir el significado principal, descartando los significados secundarios;

- transmitir el significado más cercano en el cuerpo del texto, haciendo referencia a los otros significados en notas aclaratorias; 


\section{LA TRADUCCIÓN DE TEXTOS DE CONTENIDO ISLÁMICO... \\ DR. AHMED KAMAL ZAGHLOUL}

- explicar en varias frases lo que quieren decir las pocas frases del Corán o del Hadiz.

Esto justifica el hecho de que varias traducciones del Corán están salpicadas de notas aclaratorias.

Los textos no sagrados no son revelados desde Alá; son textos de varia índole, redactados por distintos escritores, de rangos muy variados, y a lo largo de muchos años, desde el período del mismo Profeta hasta nuestros días. Casi todos estos textos giran en torno a los textos sagrados, pues se tratan de explicaciones e interpretaciones de los mismos. Los ulemas e imanes del Islam se han esforzado en sacar las sentencias de la jurisprudencia islámica a partir del Corán y del Hadiz. Por eso, aunque sus textos no son sagrados, contienen casi siempre referencias a las aleyas coránicas y a los hechos y dichos del mensajero Muhammad. El lenguaje de estos textos es muy variado: los antiguos están escritos en un árabe culto clásico, y los modernos están escritos, en su mayoría, en árabe culto moderno. Los receptores de dichos textos también son distintos, de acuerdo con el grado de antigüedad del texto. El traductor de estas escrituras no encuentra muchas ambigüedades; puede recurrir al contexto para precisar el significado, puesto que el texto no acepta varias interpretaciones.

Los textos modernos de contenido islámico están destinados al público en general, es decir, no se enmarcan dentro de la traducción especializada. El árabe estándar moderno utilizado, por ejemplo, en los sermones y fetuas islámicos, puede ser entendido por casi todos los receptores. Sin embargo, los textos escritos en árabe clásico, tanto sagrados como no sagrados, presentan unas características léxicas y morfosintácticas diferenciadoras, razón por la cual pueden formar parte de la traducción especializada, ya que no todos los receptores actuales son capaces de percibir su significado y 


\section{LA TRADUCCIÓN DE TEXTOS DE CONTENIDO ISLÁMICO... \\ DR. AHMED KAMAL ZAGHLOUL}

requieren del traductor una serie de conocimientos especiales. Para entender los textos especializados, en general, el traductor profesional debe dominar, según Gamero Pérez (1996: 195), cinco niveles que el estudiante debe aprender:

1. conocimientos extralingüísticos sobre el campo temático;

2. dominio de la terminología específica;

3. capacidad de razonamiento lógico;

4. reconocimiento de tipo y géneros textuales;

5. capacidad para documentarse.

Por otro lado, los textos islámicos, tanto sagrados como no sagrados, pueden clasificarse según el campo temático en actos de adoración, como la oración, el ayuno, el azaque, la peregrinación, etc.; actos de transacción y relaciones sociales, como la compraventa, el matrimonio, el divorcio, etc.; creencia en la Unicidad de Dios, que se divide en la Unicidad de la señoría de Dios, la Unicidad de Divinidad y la Unicidad de los nombres y atributos de Dios; veredictos de la recitación articulada del Corán; y biografía del Profeta y de los Califas ejemplares; entre otros temas. Podría ser difícil encontrar textos que se refieran exclusivamente a una sola categoría temática de las antes mencionadas. La exégesis de una aleya coránica, por ejemplo, suele aparecer junto a la interpretación de un dicho o hecho del Profeta, una historia de la vida del Profeta, una sentencia de la jurisprudencia, etc.

En cuanto a la función del lenguaje puede variar de un texto a otro. No obstante, la función predominante en la mayor parte de los textos islámicos, en especial, y los religiosos, en general, es la apelativa o conativa. En casi todos los textos apologéticos se espera del receptor que reaccione de una 


\section{LA TRADUCCIÓN DE TEXTOS DE CONTENIDO ISLÁMICO... \\ DR. AHMED KAMAL ZAGHLOUL}

forma determinada, que haga algo o deje de hacer algo. El escritor de los textos religiosos pretende normalmente influir en la conducta de los lectores, a través de dar mandatos y consejos, y utilizar recursos lingüísticos como los vocativos, modo imperativo, oraciones interrogativas, utilización deliberada de elementos afectivos, adjetivos valorativos, términos connotativos y toda la serie de recursos retóricos. Algunas frases que aparentemente son referenciales o informativas también pueden esconder una función apelativa, es decir, se invita, mediante estas frases, al receptor a que haga algo. La función estética aparece claramente en los textos sagrados, como las aleyas coránicas y los dichos del Profeta, considerados, según la creencia islámica, como milagros en sí, tanto al nivel del contenido como al de la forma. Asimismo, la función argumentativa es la que prevalece en textos como los de creencia en la Unicidad de Dios y de jurisprudencia.

En lo que se refiere al modo y al tono, los textos islámicos pueden ser orales (como el sermón del viernes), pero la mayoría son textos escritos, y su tono es extremadamente formal.

\section{4) La competencia documental}

Uno de los objetivos más importantes de la enseñanza/aprendizaje de la traducción especializada, en general, es la adquisición de la competencia documental. Según Roberto Mayoral (1994: 118), "el trabajo de traducción es en gran medida un problema de documentación". En este mismo contexto, Elena García (1996: 89-90) afirma:

"El traductor debe aprender a reflexionar realizando previamente una buena documentación, sólo de esta manera podrá obtener todos los datos necesarios para relacionar las posibilidades de intercambio entre las dos lenguas y culturas. El 


\section{LA TRADUCCIÓN DE TEXTOS DE CONTENIDO ISLÁMICO... \\ DR. AHMED KAMAL ZAGHLOUL}

que traduce está obligado por su profesión a buscar y encontrar soluciones, a recoger y seleccionar datos, en definitiva, a saber disponer de toda la información posible".

El docente de la traducción de textos islámicos debe, pues, hacer a los alumnos familiarizarse con el uso de obras de referencia relacionadas con el lenguaje especializado de esta modalidad de traducción. El estudiante necesita saber, desde el comienzo del curso, a qué fuente de referencia debe recurrir en caso de buscar la definición de un término islámico o, lo que es lo mismo, cuáles son los diccionarios y otras obras de referencia que le pueden servir en la traducción de los textos islámicos. Los objetivos específicos serían, pues, conocer tales fuentes, adquirir habilidad en manejarlas de forma eficaz, y saber cuándo hay que utilizar cada fuente.

Se puede clasificar las fuentes de documentación para la traducción de textos islámicos de la manera siguiente:

1) Diccionarios generales: monolingües - bilingües. A saber, entre los diccionarios que se utilizan más en el campo de la traducción árabeespañol destacan los de los arabistas españoles Julio Cortés y Federico Corriente.

2) Diccionarios de términos islámicos. Entre este tipo de diccionarios destacan el Glosario de voces coránicas (2006), de Serry Abdel Latif, Zidan Abdel Halim y El Sayed Abdel Zaher; Glosario de términos de la llamada al Islam (2006) de Nasser Ben Saleh AlMansour y Zidan Abdel Halim; y el Diccionario de términos islámicos, en línea, de Bahige Mulla Huech. 


\section{LA TRADUCCIÓN DE TEXTOS DE CONTENIDO ISLÁMICO...}

DR. AHMED KAMAL ZAGHLOUL

3) Libros y artículos de contenido islámico traducidos al español, como las traducciones del Corán, la exégesis coránica, el Hadiz profético, las fetuas, los sermones...

4) Escritos árabes sobre las distintas disciplinas del Islam.

5) Recursos internéticos relacionados con el lenguaje apologético español. Como ejemplos de estas páginas web se puede hacer referencia a las Fatwas del Comité Permanente de la Presidencia General de Investigaciones Científicas y Emisión de Fatwas del Reino de Arabia Saudita (http://www.alifta.net), Islam House (http://www.islamhouse.com), $\quad$ Islam para todos (http://islamparatodos.org), Revista Luz del Islam (http://luzdelislam.com), el Hadiz (http://hadiz.net), Islam question and answer (http://www.islam-qa.com/es), etc.

6) Consulta con ulemas, imanes y líderes espirituales del Islam.

Sería necesario al comienzo del curso que el docente preparara y pusiese a disposición del alumnado una lista con los diversos materiales considerados como herramientas indispensables del traductor de textos islámicos. Proporcionar a los estudiantes estos materiales y hacerles practicar la documentación dentro y fuera de la clase les ayudaría a solucionar muchos problemas con los cuales podrían enfrentarse durante el proceso de la traducción. A este respecto, el alumno debe aprender a desconfiar de los diccionarios bilingües, a apoyarse más en las obras de referencia relacionadas directamente con los textos islámicos, y a tener en cuenta el contexto en que aparecen, sobre todo, las palabras polisémicas. 


\section{5) Dominio de la terminología islámica}

El texto islámico, igual que los textos especializados en otros campos temáticos, se caracteriza por la presencia de una terminología concreta, propia de esta área de especialidad. Como los términos actúan como "elementos de transmisión del conocimiento experto, y el hecho de desconocer su significado supone un importante obstáculo para la traducción" (Barceló Martínez, 2011: 33), los traductores deben dominar la terminología y la fraseología propias del ámbito islámico para ser capaces de resolver adecuadamente los problemas terminológicos a los cuales se enfrentan.

Actualmente, dotar a los futuros traductores e intérpretes de una formación básica en los fundamentos teóricos de la terminología y en sus principios metodológicos se considera, según Fijo León (2007: 193), "una necesidad incuestionable, como demuestra la inclusión de la asignatura Terminología en los planes de estudios de la Licenciatura en Traducción e Interpretación". Si el dominio de la terminología es, en sí, un objetivo general de dicha asignatura que forma parte del plan de estudios de Traducción, en el plan de estudios de Lengua Española este objetivo general se convierte en uno de los objetivos específicos de las distintas asignaturas de traducción especializada, ya que sería difícil incluir la asignatura de la terminología en un programa de lengua.

El docente de la asignatura de Traducción Islámica debe, por tanto, prescindir de impartir los contenidos teóricos relativos a la disciplina de la terminología, como su historia y sus diferentes escuelas y tendencias, ayudando directamente a los alumnos a aprender las habilidades prácticas relativas a la gestión de terminología islámica, las cuales pueden ser resumidas de la manera siguiente: 


\section{LA TRADUCCIÓN DE TEXTOS DE CONTENIDO ISLÁMICO...}

DR. AHMED KAMAL ZAGHLOUL

1) Elaborar un glosario de términos islámicos a partir de los textos trabajados durante el curso.

2) Ayudar a que cada uno de los alumnos cree su propia base de datos terminológica, dado que los diccionarios no pueden recoger todos los términos islámicos.

3) Saber las características de los buscadores internéticos y cómo utilizarlos.

4) Distinguir entre el significado de los términos que, aunque podrían considerarse como sinónimos en los textos generales, suelen tener un significado diferente en los textos apologéticos, como, por ejemplo, (رسول، نبي؛ رب، إله؛ صدقة، زكاة)

5) Reducir a lo mínimo la subjetividad que acecha al traductor a la hora de transmitir términos específicos. Esto quiere decir que el alumno no debe improvisar nada, y que debe aprender a utilizar el término que más se utiliza en la documentación de referencia si existe. Si no, pues puede, en este caso, crear su propia terminología.

Uno de los ejercicios que más puede ayudar a los alumnos a adquirir el espíritu crítico de un traductor de textos islámicos, en general, y la competencia terminológica, en especial, es el de la traducción paralela. El docente entrega a los alumnos varias traducciones de un solo texto, por ejemplo, la traducción de algunas aleyas coránicas según aparecen en varias versiones españolas del Corán, y les pide que comparen y reflexionen sobre 


\section{LA TRADUCCIÓN DE TEXTOS DE CONTENIDO ISLÁMICO... \\ DR. AHMED KAMAL ZAGHLOUL}

la metodología de la traducción de la terminología de cada una, ayudándoles a llegar, por sí mismos ${ }^{3}$, a las conclusiones siguientes:

1) A veces no le corresponde a un mismo concepto un único término.

2) Algunos términos islámicos no tienen equivalentes, o, al menos, son difíciles de traducir, razón por la cual el traductor se ve obligado a utilizar explicaciones o notas aclaratorias como estrategias para transmitir este tipo de términos.

3) Hay varios motivos que pueden causar la diferencia de equivalentes propuestos por los traductores, entre los cuales se puede hacer referencia a la diferencia del receptor (musulmán o no musulmán ${ }^{4}$, español o hispanoamericano) y de la exégesis coránica en que se basa el traductor.

4) El contexto es el que determina, en muchas ocasiones, el equivalente adecuado del término.

Otro ejercicio que puede reportar mayores beneficios a los alumnos, ayudándoles a crear su propia base de datos terminológica es el de la

\footnotetext{
${ }^{3}$ Según Barceló Martínez (2011: 36), "resulta más beneficioso que sea el propio alumno quien lleve a cabo los procesos de documentación y de comparación terminológica y conceptual y que no sea el profesor quien proporcione toda esa información directamente".

4 Cabe señalar que los lectores hispanohablantes musulmanes, aunque no saben la lengua árabe, suelen preferir, por razones religiosas, que el traductor transmita algunos términos árabes utilizando las letras de la transcripción del alfabeto árabe, es decir, dejar los términos sin traducción al español (por ejemplo, Salat, Zakat, Shahada...), ya que esto les ayuda a enterarse de conceptos islámicos. A los no musulmanes no les agrada, evidentemente, que la traducción esté salpicada de términos árabes no susceptibles de ser entendidos.
} 


\section{LA TRADUCCIÓN DE TEXTOS DE CONTENIDO ISLÁMICO... \\ DR. AHMED KAMAL ZAGHLOUL}

traducción inversa, del español al árabe. En este ejercicio resulta más fácil a los alumnos identificar los términos islámicos y sus colocaciones dentro de la frase.

En cuanto al ejercicio natural y más utilizado en esta modalidad de textos, el del árabe (lengua normal de los textos islámicos) al español, se notará que algunos alumnos se lanzarán en una traducción extremadamente literal, algo que le permite al docente corregir esta tendencia. Resulta conveniente en este ejercicio que el profesor pregunte a los alumnos por el sentido del término árabe, para ver si lo entienden bien, y por las fuentes en las que lo han encontrado, para asegurarse de que están escritas en lengua española aceptada.

\section{3) La selección de textos}

Los textos pensados para el aula de traducción religiosa deben ser elegidos a partir de los objetivos de la enseñanza/aprendizaje de la traducción de textos islámicos que hemos detallado hasta ahora. Por lo tanto, seleccionar textos adecuados para las tareas de traducción religiosa dentro del aula exige al docente que conteste primero a la pregunta siguiente: ¿qué es lo que deben aprender los alumnos para conseguir los objetivos de la enseñanza de esta asignatura?

A la hora de elegir los textos, el docente debe tener en cuenta que el objetivo es mantener siempre viva la motivación de los aprendices. Partiendo de este objetivo, el docente debe elegir textos:

- auténticos, pues de este modo se puede asimilar el mercado laboral;

- adecuados para el nivel de conocimientos de los estudiantes;

- graduados, empezando por textos religiosos más sencillos, y terminando con textos de mayor grado de especialidad, o, lo que es lo 


\section{LA TRADUCCIÓN DE TEXTOS DE CONTENIDO ISLÁMICO...}

DR. AHMED KAMAL ZAGHLOUL

mismo, hay que establecer una progresión en la dificultad de los textos, teniendo en cuenta que dicha dificultad no tiene nada que ver con la longitud del texto;

- de clases textuales variadas (exégesis del Corán, dichos del Profeta, fetuas, sermones...);

- de temas distintos (actos de adoración, buenos modales, monoteísmo, biografía del Profeta...);

- de lenguaje árabe culto moderno, al menos en su mayoría, dado que esta asignatura no forma parte de un plan de estudio de traducción, sino de lengua, y que los textos escritos en árabe clásico presentan dificultades considerables que puedan desmotivar a los alumnos;

- que tengan importancia en el mercado laboral, de modo que se da preferencia, por ejemplo, a la traducción de las fetuas que a la del Corán;

- que tengan varios términos islámicos para comprobar el dominio de la terminología;

- que no sean extremadamente fáciles o difíciles, ya que los primeros no dejan espacio para ejercer la documentación, y los últimos no garantizan una actitud positiva por parte de los alumnos; y

- que expongan distintas opiniones de la jurisprudencia islámica, de modo que algunas de ellas sean contrarias a las adoptadas por el alumnado con el propósito de familiarizarse con la ética del traductor de textos islámicos, según la cual éste no debe intervenir en la traducción, aunque el contenido del texto sea contrario a su propia doctrina, ya que, como se sabe, el traductor no produce un texto nuevo, sino que lo reproduce. 


\section{LA TRADUCCIÓN DE TEXTOS DE CONTENIDO ISLÁMICO...}

DR. AHMED KAMAL ZAGHLOUL

En cuanto a la variedad del tipo de texto y del tema, exponemos en la tabla siguiente un ejemplo de cómo se puede seleccionar los textos partiendo de la clase del texto (plano vertical) y de la temática (plano horizontal) a la vez:

\begin{tabular}{|c|c|c|c|c|c|}
\hline Tema de texto & La oración & $\begin{array}{l}\text { Los pilares } \\
\text { del Islam }\end{array}$ & La mujer & $\begin{array}{c}\text { Los buenos } \\
\text { modales }\end{array}$ & $\begin{array}{c}\text { La unicidad } \\
\text { de Dios }\end{array}$ \\
\hline Tipo de texto & & & & & \\
\hline Exégesis del & $1^{\mathrm{a}}$ & & & & \\
\hline Corán & semana & & & & \\
\hline Dichos del & & $2^{\mathrm{a}}$ & & & \\
\hline Profeta & & semana & & & \\
\hline Fetua & & & $\begin{array}{c}3^{a} \\
\text { semana }\end{array}$ & & \\
\hline $\begin{array}{c}\text { Sermón } \\
\text { del viernes }\end{array}$ & & & & $\begin{array}{c}4^{\mathrm{a}} \\
\text { semana }\end{array}$ & \\
\hline Creencia & & & & & $\begin{array}{c}5^{\mathrm{a}} \\
\text { semana }\end{array}$ \\
\hline
\end{tabular}




\section{LA TRADUCCIÓN DE TEXTOS DE CONTENIDO ISLÁMICO... \\ DR. AHMED KAMAL ZAGHLOUL}

\section{Conclusiones}

La didáctica de la traducción de textos de contenido islámico debe partir de objetivos generales y específicos determinados. El docente debe dar a conocer tales objetivos al alumnado desde el inicio del curso porque conocerlos de una forma clara desde el principio permite a los alumnos tener claridad acerca de qué es lo que deben aprender.

El presente estudio deja constancia de que la enseñanza de la traducción islámica de una forma inversa no contradice los criterios metodológicos de la teoría de la traducción porque es una de las exigencias del mercado laboral en un país como Egipto. A este respecto, el docente debe aprovechar esta ocasión para hacer una aproximación al funcionamiento del mercado laboral.

Sería importante, también desde el principio del curso, que el docente proporcionara una lista con las fuentes de referencia, tanto en papel como internéticas, necesarias para desarrollar la traducción de textos islámicos; explicara la tarea final del curso, que podría consistir en elaborar un glosario de términos islámicos a partir de los textos trabajados durante el curso; y expusiera un modelo de un texto islámico analizado, de modo que el texto elegido cuenta con un gran número de los problemas traductológicos que puede enfrentar el traductor de textos islámicos. La traducción de este texto también debe ser adjuntada para que los alumnos tengan una idea sobre las técnicas y estrategias que pueden utilizar para resolver dichos problemas.

La selección de los textos pensados para el curso de traducción religiosa debe hacerse de una forma intencionada, de modo que el alumnado reconoce tanto los tipos y características de los textos islámicos como los problemas traductológicos que puede enfrentar en el mercado laboral. Una 


\section{LA TRADUCCIÓN DE TEXTOS DE CONTENIDO ISLÁMICO... \\ DR. AHMED KAMAL ZAGHLOUL}

de las competencias que puede ayudar mucho a los alumnos a solucionar estos problemas es la temática. Por eso, el docente debe dirigir la atención de los alumnos hacia la importancia de sacar provecho de los conocimientos islámicos que estudian durante la carrera para formar una competencia temática en el ámbito de la traducción de textos islámicos.

Por otro lado, como reacción ante tanto los actos terroristas cometidos en nombre del Islam como la propagación del fenómeno de la "islamofobia", es imprescindible difundir el espíritu verdadero del Islam, algo que puede realizarse especialmente a través de la traducción de los textos islámicos, lo que necesita, por supuesto, aprender los fundamentos de la traducción de esta modalidad de textos. Los investigadores, sobre todo árabes, deben prestar más atención a los estudios que tienen por objetivo formar a traductores de textos islámicos, dado que los estudios realizados sobre la didáctica de la traducción en España, entre otros países interesados en estudiar la teoría de la traducción, se concentran, por razones relacionadas con el mercado laboral, en modalidades como la traducción médica, jurídica, económica..., pero no la religiosa, y aún menos la islámica. 


\section{LA TRADUCCIÓN DE TEXTOS DE CONTENIDO ISLÁMICO... \\ DR. AHMED KAMAL ZAGHLOUL}

\section{Bibliografía}

Barceló Martínez, Tanagua (2011): "Adquisición de conocimiento experto y terminología en el proceso de enseñanza-aprendizaje de la traducción especializada (ámbitos jurídico y técnico)". En Anales de Filología Francesa, nº 19, 25-39.

Beeby Lonsdale, A. (1996): Teaching Translation from Spanish to English. Ottawa: University of Ottawa Press.

Cómitre Narváez, Isabel (2003): "La enseñanza de la traducción inversa (español-francés): realidad profesional y desafío didáctico", en Ricardo Muñoz Martín (ed.), I AIETI. Actas del I Congreso Internacional de la Asociación Ibérica de Estudios de Traducción e Interpretación. Granada 12-14 de Febrero de 2003. Granada: AIETI, Vol. 2, 383-389.

Elena García, Pilar (1996): "La documentación en la traducción general", en Amparo Hurtado Albir (ed.), La enseñanza de la traducción. Castellón: Universitat Jaume I, Col.lecció Estudis sobre la Traducció, 3, 79-90.

(2007): "Reflexiones en torno a la enseñanza de la traducción especializada". En Panace@, nº 26, 101-102.

Fijo León, M. ${ }^{a}$ Isabel (2007): "La enseñanza de la terminología a los alumnos de Traducción e Interpretación: el caso de la Universidad Pablo de Olavide". En Panace@, nº 26, 193-198. 


\section{LA TRADUCCIÓN DE TEXTOS DE CONTENIDO ISLÁMICO...}

DR. AHMED KAMAL ZAGHLOUL

Gamero Pérez, S. (1996): —La enseñanza de la traducción científicotécnicall, en La enseñanza de la traducción. Castelló de la Plana: Publicacions de la Universitat Jaume I.

Hurtado Albir, Amparo (2001): Traducción y traductología: Introducción a la traductología. Madrid: Cátedra.

Kelly, Dorothy A. (2002): "Un modelo de competencia traductora: bases para el diseño curricular". En Hacia nuevas investigaciones en la mediación intercultural, $\mathrm{n}^{\circ}$ 1, 9-20.

Mayoral, Roberto (1994): "La documentación en la traducción", en Javier de Agustín (ed.), Traducción, interpretación, lenguaje. Madrid: Fundación Actilibre, 107-118.

Mulla Huech, Bahige: Diccionario de términos islámicos. Disponible en http://www.diccionarioterminosislamicos.com (fecha de consulta: 22/12/2014).

Nasser Ben Saleh Al-Mansour y Zidan Abdel Halim (2006): Glosario de términos de la llamada al Islam. Riad: Universidad del Rey Saúd.

Newmark, Peter (1988): A textbook of Translation. Londres: Prentices Hall (Manual de traducción. Madrid: Cátedra, 1992).

Roiss, S. (2001): "El mercado de la traducción inversa en España: un estudio estadístico". En Hermeneus (Revista de traducción e interpretación), Vol. 3, 379-408. 


\section{LA TRADUCCIÓN DE TEXTOS DE CONTENIDO ISLÁMICO...}

DR. AHMED KAMAL ZAGHLOUL

Serry Abdel Latif, Zidan Abdel Halim y El Sayed Abdel Zaher (2006): Glosario de voces coránicas. El Cairo: Osiris editorial.

Wimmer, Stefanie (2011): El proceso de la traducción especializada inversa: Modelo, validación empírica y aplicación didáctica (Tesis inédita). Barcelona: Universidad Autónoma de Barcelona. 